\title{
EQUIVALENCIA DE LAS MONEDAS \\ CASTELLANAS EN LA CORONA DE ARAGÓN, EN TIEMPOS DE FERNANDO EL CATÓLICO
}

Jordi Ventura

En el período de transición histórica que constituyó el reinado de Fernando el Católico, los diferentes reinos de la Corona española tenían. como es natural, monedas diversas que no siempre coincidían en su valor intrínseco y circulatorio.

La documentación de la época nos ha conservado pruebas suficientes, en número variable según su interés y abundancia, que nos pueden dar una idea bastante adecuada de cuáles eran las equivalencias entre unas monedas y otras. La historiografía económica reciente ha comenzado a otorgar una importancia central a la cuestión de los cambios monetarios, con una atención cada vez más acentuada hacia las técnicas utilizadas y el pleno desarrollo de los sistemas monetarios. Personalmente, llevo publicados ya o tengo en prensa, a punto de aparecer, varios estudios sobre las equivalencias establecidas y los procedimientos paritarios que, a lo largo de todo el antiguo régimen y más allá, estuvieron vigentes y se utilizaron en los métodos de cambio entonces sólo incipientes.

En lo que se refiere a la época del Rey Católico, he realizado sendos estudios respecto a dichas equivalencias, uno sobre Valencia y otro sobre Cataluña'. En ambos he hecho a menudo uso de una fuente documental, ciertamente no menor, que es la compuesta por los registros de las receptorías inquisitoriales que, conservados en Valencia, Madrid y Barcelona, nos ofrecen la garantía del rigor - a veces puntillista- de las autoridades del tribunal de la Inquisición y la extraordinaria minucia con que tomaron nota de los detalles aparentemente más insignificantes.

Ahora, tomando como fuente de base la documentación inquisitorial y la práctica mercantil de la época, he pensado ofrecer unas conclusiones

I \&Les equivalències monetàries oficials a Catalunya a principis de I'Edat Modernas, Primer Congrés d'Història Moderna de Catalunya, vol. I, p. 435-441, Barcelona 1984. 
centradas en el estudio de las paridades oficiales que regían para las monedas castellanas, así como, en la medida de lo posible, las divergencias que surgían dentro del mismo módulo establecido oficialmente.

\section{EQUIVALENCIA DEL DUCADO}

Todas las monedas de Castilla venían definidas por su equivalencia en maravedís. El maravedí era una moneda castellana muy antigua, creada por Alfonso VIII a imitación de la moneda musulmana. Con el tiempo, experimentó una progresiva depreciación en su valor, lo que al final provocó asimismo que acabara siendo acuñado sólo en cobre, muy lejos ya de sus lejanos orígenes áureos del siglo XII. Lo que no fue sino el preludio a su conversión en simple moneda de cuenta.

Por otra parte, además de sus múltiplos, persistieron los submúltiplos del maravedí. Las subdivisiones del maravedí eran la blanca, o 1/2 maravedí; el cornado, o 1/6 de maravedí; el dinero, o 1/10; y la meaja, o 1/60.

Constituyó, sin embargo, la principal referencia monetaria de los reinos castellanos y nada tiene de extraño, pues, que la noticia de cantidades expresadas en maravedís aparezca en los documentos de las receptorías inquisitoriales de la corona de Aragón.

Como muy a menudo los nuevos oficiales de la Inquisición eran súbditos originarios de tierras de la Corona de Castilla, al comenzar sus funciones se les asignaba el salario en moneda castellana. Y, lógicamente, una vez pagados, el receptor que actuaba en uno u otro territorio ajeno a tierras castellanas anotaba el monto en sus cuentas, tanto en moneda de Castilla como en su equivalente en moneda local. Cuando de moneda castellana se trataba, la relación se efectuaba a través de la paridad oficial de 1 ducado $=$ 375 maravedís, establecída oficialmente por la pragmática real fechada en Medina del Campo el 13 de junio de 1497.

Efectivamente, cuando el 22 de diciembre de 1497 el licenciado Fernando de Montemayor, arcediano de Almazán, fue nombrado inquisidor y juez de bienes confiscados en el distrito del tribunal de Barcelona, el rey ordenó que le pagasen un salario, "en cada un anyo, de cient mil maravedís, moneda de Castilla, o su valor en moneda barcelonesa, contando a razón de trezientos setenta cinco maravedís el ducado ${ }^{2}$ ».

Como en Barcelona, por aquellos años, el cambio oficial del ducado de oro era de 24 sueldos barceloneses, esto venía a significar un salario anual, en moneda barcelonesa y al cambio oficial de la moneda de cuenta, de:

${ }^{2}$ AHN, Inquisición, libro 242, f०. 11. Documento núm. 107, p. 299-300, del volumen III de mi tesis doctoral, La inquisición española y los judios conversos barceloneses. (Siglos XV y xvi), 
$100.000 \mathrm{~ms} . / 375 \mathrm{~ms} .=266,6666667$ D. Y 266,6666667 D. $\times 24 \mathrm{~s} . \mathrm{B}^{\mathrm{a}} \cdot$ por $D_{1}=6.400 \mathrm{~s} . \mathrm{B}^{\mathrm{n}}, \mathrm{o}$ sea $320 \mathrm{E}$. $\mathrm{B}^{\mathrm{x}}$.

En proporción, y matemáticamente hablando, en cada sueldo barcelonés había la relación siguiente: $100.000 \mathrm{~ms} . / 6.400 \mathrm{~s}$. B ${ }^{\star} .=15,625 \mathrm{~ms}$. por cada sueldo barcelonés. Y en cada dinero, 1,302083333 ms.

Ya antes del decreto real de 1497, el cambio del ducado se efectuaba sobre la base de una paridad de $375 \mathrm{~ms}$. Por lo menos era así en Valencia, que poseía una de las monedas más valoradas de la corona española.

El 17 de marzo de 1496, el repostero de plata del rey, Diego de Aramayo, cobraba una parte de una merced real, que Fernando el Católico le había hecho en Barcelona el 29 de agosto de $1493^{3}$.

Los receptores inquisitoriales, como siempre, eran remisos en pagar esta clase de dádivas reales que, en este caso, ascendía a 50.000 maravedís. Pero, finalmente, el receptor de Valencia, Amador de Aliaga, inscribió en su registro que le pagaba a Aramayo eveynte y dos ducados de oro en oro y dos solidos ocho dineros, moneda reales de Valencia». O sea: 22 D. 2 s. 8 d. Y añadía Aliaga: «que son, moneda de Castilla, ocho mill dozientos noventa y ocho maravedís» $(8.298 \mathrm{~ms}$.).

Como el ducado valía en Valencia $21 \mathrm{~s} . \mathrm{V}^{\mathrm{a}}$, , tenemos: $1 \mathrm{D},=21 \mathrm{~s} . \mathrm{V}^{\mathrm{a}}, \mathrm{y}$ 22 D. 2 s. 8 d. $=5.576$ d. $V^{a} ., 8.298 \mathrm{~ms} . / 5.576 \mathrm{~d}$. $=1,488163558 \mathrm{~ms}$. por d. $\mathrm{V}^{\mathrm{a}} .1,488163558 \mathrm{~ms}, \mathrm{x} 12=17,8579627 \mathrm{~ms}$. por s. $\mathrm{V}^{\mathrm{a}}$. $17,8579627 \mathrm{~ms}$. $\mathrm{x}$ $21 \mathrm{~s} .=375 \mathrm{~ms}$. y 1 meaja.

De modo que si, en 1496,1 dinero valenciano valía 1,488163558 maravedís y 1 sueldo $17,8579627 \mathrm{~ms}$., es evidente que 21 sueldos, o sea 1 ducado de oro, equivalían prácticamente a 375 maravedís, despreciando la meaja sobrante, al tener en cuenta los rudimentarios procedimientos contables utilizados entonces.

De entre los muchos casos similares realizados después en Valencia, notemos cómo, en 1498, el inquisidor Rodrigo Sanz de Mercado se le pagaban, por cada tercia de sus haberes anuales, la cantidad de 33.333 maravedís y 2 cornados, a través de su paridad valenciana de 1.878 sueldos y 6 dineros 4 .

$33.333,33333 \mathrm{~ms} .=22.542 \mathrm{~d} . \mathrm{V}^{\mathrm{a}}$. Y $33.333,33333 \mathrm{~ms} . / 22.542 \mathrm{~d} . \mathrm{V}^{\mathrm{a}} .=$ 1,478721202 ms. por cada d. $V^{a}$. Lo que constituía una muy ligera diferencia con el cálculo efectuado a través de la paridad oficial del ducado en maravedís.

Más diversa fue ya la paridad, dada en el mismo año 1498, al hacerse efectiva la tercia correspondiente al salario del abogado fiscal del tribunal de Valencia, bachiller Francisco de Oropesa, abad de Toro, que fue de

${ }^{3} \mathrm{AHN}$, Inq. legajo $568,1496, \mathrm{f}^{\circ}, 79 \mathrm{v}^{\circ}$.

${ }^{4} \mathrm{AHN}$, Inq., leg. $568,1498, \mathrm{f}^{\circ}, 30 \mathrm{r}^{\circ}$. 
16.666 maravedís y 4 cornados ${ }^{3}$. La equivalencia anotada en moneda valenciana era de 938 s. 3 d. De modo que: $16.666,6666666668 \mathrm{~ms} . / 11.255 \mathrm{~d}$. $\mathrm{V}^{\mathrm{a}},=1,480823338 \mathrm{~ms}$. que, según la equivalencia resultante, era el valor que correspondía en maravedís al dinero valenciano. Casi, pero no exactamente, la equivalencia anterior; sólo apreciable en grandes cantidades, pero que, de todas maneras, en el caso que nos ocupa, significaba nada menos que $23 \mathrm{~ms}$. y 1 blanca de más o 16 dineros de más en moneda valenciana.

Por lo que respecta a la paridad con la moneda jaquesa, de Aragón, habría tenido que ser de $1 \mathrm{~s} . \mathrm{J}^{\mathrm{a}} .=17,04545455 \mathrm{~ms}$. y $1 \mathrm{~d}$. $\mathrm{J}^{\mathrm{a}} .=1,420454546$ $\mathrm{ms}$. Siendo el valor oficial del ducado de $22 \mathrm{~s}$. jaqueses, es indudable que $375 \mathrm{~ms} / 22 \mathrm{~s} . \mathrm{J}^{\mathrm{a}}=17,04545455 \mathrm{~ms}$. y $375 \mathrm{~ms} / 264 \mathrm{~d}$. $\mathrm{J}^{\mathrm{a}}=1,420454546 \mathrm{~ms}$.

Pero la discrepancia práctica se ponía a veces de manifiesto. Como al hacerse efectiva otra parte de la dádiva de 50.000 maravedís, que el rey había concedido a su repostero de plata, Diego de Aramayo. Una parte del pago, la última, se efectuaba a través de la aljama musulmana de Ejea, que le entregó directamente 2.500 sueldos de moneda jaquesa; el receptor de Valencia anotó, al mismo tiempo, la equivalencia de 2.343 s. 9 d. de moneda valenciana ${ }^{6}$.

O sea, como $2.500 \mathrm{~s} . \mathrm{J}^{\mathrm{a}} \cdot / 2.343,75 \mathrm{~s} . \mathrm{V}^{\mathrm{a}}=1,066666667$, éste el valor en sueldos jaqueses del sueldo valenciano.

Sin embargo, pasando a través del ducado, la paridad habría debido ser: $22 \mathrm{~s} . \mathrm{J}^{\mathrm{a}} / 21 \mathrm{~s} . \mathrm{V}^{\mathrm{a}}=1,047619048$, una diferencia de $0,19047619 \mathrm{~s} . \mathrm{J}^{\mathrm{a}}$. de más. de acuerdo con las cuentas de la receptoría.

De modo que es posible que, si el sueldo valenciano resultaba evaluado en $1,78571428 \%$ de más con respecto al sueldo jaqués, la equivalencia de éste en maravedís disminuyera asimismo proporcionalmente. Si se habían pagado ya 8.298 maravedís, faltaban pues $41.702 \mathrm{~ms}$. a cumplimiento de pago de la dádiva. La aljama entregó $2.500 \mathrm{~s}$. Ja., así que $41.702 \mathrm{~ms} . / 2.500$ $\mathrm{s}$. $\mathrm{J}^{\mathrm{a}}=16,6808 \mathrm{~ms}$. por cada $\mathrm{s}$. $\mathbf{J}^{\mathrm{a}}$., una cifra más aproximada a los $16,74107143 \mathrm{~ms}$. (que corresponden matemáticamente al $1,78571428 \%$ de disminución) que no a los $17,04545455 \mathrm{~ms}$. de la paridad oficial.

\section{EL CASTELLANO DE ORO}

El castellano ${ }^{7}$ era una moneda de oro igual a la centésima parte de una libra de peso en oro. En cuestiones monetarias, el oro se pesaba en Castilla

5 Ibíd. $\mathrm{f}^{\circ}, 31$ y $34 \mathrm{r}^{\circ}$

${ }^{6} \mathrm{AHN}$, Inq, leg. $568,1499, \mathrm{f}^{\circ}, 34 \mathrm{v}^{\circ}$

7 Véase A. SÁszDI, «Spain and american treasure: the depreciation of silver and monetary exchange in the viceroyalty of Lima, 1550-1610w. The Journal of European Economic History, volumen 4, núm. 2,1975, p. $432-433$. 
a base del marco (o sea, 1/2 libra), el cual se subdividía en 50 castellanos, cada castellano en 8 tomines y cada tomín en 12 granos. De manera que, según estas divisiones teóricas, un castellano de oro tenía 96 gramos. La libra castellana, o libra de Ávila (que por otra parte, en cuestiones no monetarias, se subdividía en 16 onzas) venía a ser igual a unos 460 gramos; y, por lo tanto, un castellano tenía 4,6 gramos de oro de «buen peso».

No sé si castellana, en lugar de castellano, era una expresión propia del catalán; pero el caso es que, a veces, el castellano aparece mencionado en femenino en la documentación que manejamos. Tal vez era que, con ello, querían diferenciar el castellano de oro del real castellano de plata, de un valor muy inferior, como es lógico.

La equivalencia oficial para esta moneda resulta ser de 27 s. 4 d. en moneda valenciana. Era el valor que le era dado explícitamente en un documento del 6 de febrero de 1493, al dar cuenta de unas piezas de oro, que una acusada inquisitorial, Violant Domènech, declaró que había encontrado en el albardón de una niña, hermana suya e hija de su madrastra, quemada en la hoguera, la cual, estando en la cárcel, las ocultó alli.

Probablemente, antes de ser ejecutada, la madre había escondido unas cuantas monedas de oro entre las ropas de la niña, con el fin de que ésta pudiese disponer de algún caudal después de la absoluta pérdida de bienes que padecería una vez condenada la progenitora. Como vemos, no sirvió de nada aquella previsión. Pero nos es útil, en cambio, la indicación de la receptoría, en el sentido de que los castellanos valían entonces en Valencia 27 sueldos y 4 dineros.

El 8 de febrero del año siguiente, el valor de un castellano volvía a ser indicado como el mismo. Era con motivo del desempeño de una pieza de lienzo de dos en pua, con una tirada de 61 alnas, que había costado 9 dineros por alna (o sea, $2 £ .5 \mathrm{~s} .9 \mathrm{~d}$.) y que, por el precio inferior de un castellano de oro había sido empeñada al tintorero Lluís Saranyana. El castellano, señalan las cuentas de la confiscación, se contaba a 27 sueldos y 4 dineros.

El 31 de julio del mismo año (1494), la que nos informa es la noticia de una letra de cambio real, que el receptor había de pagar a Batista Burgarini, mercader florentino, residente en Valencia. El cambio ascendía a 8.200 sueldos, por el valor de 300 castellanos de oro en oro y de buen peso, que el rey había tomado al cambio en Medina del Campo .

La equivalencia es clara: $8.200 \mathrm{~s} / 300 \mathrm{C} .=271 / 3 \mathrm{~s} .$, o sea $27 \mathrm{~s} .4 \mathrm{~d}$.

El 7 de abril de 1496, la nota de un pago hecho al secretario Pedro de Villacis informa de que éste había cobrado 20.000 maravedís en 41 caste-

${ }^{8}$ AHN, Inq., leg, 568, 1493, $\mathrm{f}^{\circ}, 1 \mathrm{v}^{\circ}$.

${ }^{9} \mathrm{AHN}$, Inq. leg. $568,1494, \mathrm{f}^{\circ}, 77 \mathrm{r}^{\circ}$. 
llanos de oro menos 4 dineros, que en moneda valenciana ascendían a 1.127 sueldos ${ }^{10}$

Tenemos, en realidad: $20.000 \mathrm{~ms} .=41 \mathrm{1} / 4$ C. $-4 \mathrm{~d} .=1.127 \mathrm{~s} .2 \mathrm{~d}$.

Aquí la equivalencia de $1 \mathrm{C}$. $=27 \mathrm{~s} .4 \mathrm{~d}$. no les resultaba matemáticamente exacta, aunque con una mínima diferencia, que nos separa un tanto (2 d.) de la cifra que era aceptada oficialmente y que, posiblemente, debamos atribuir únicamente a la manera en que entonces acostumbraban a llevar sus cuentas.

Efectivamente, 41 i $1 / 4$ C. $\times 27$ s. 4 d. o 41,25 C. $\times 328$ d. $=13.530$ d.

$$
13.530 \mathrm{~d} .-4 \mathrm{~d} .=13.526 \mathrm{~d} .=411 / 4 \mathrm{C} .-4 \mathrm{~d} \text {. }
$$

Ahora bien, $1.127 \mathrm{~s} .=13.524 \mathrm{~d}$., con lo que se da una ligera diferencia entre una y otra equivalencia.

Imaginémonos, sin embargo, dada la defectuosidad de los métodos de cálculo que se veían obligados a utilizar —con el uso, además, de números romanos y no arábigos-, cuán deficientes habían de resultar los balances finales. Como en más de una ocasión he podido observar, las equivocaciones menudeaban y se originaban confusiones y errores, pleitos y contrapleitos que comúnmente se resolvían con multas o condonaciones reales.

En cambio, se da una coincidencia más aproximada con la equivalencia de 485 maravedís por castellano de oro a que, según una nota de E.J. Hamilton, esta moneda era contabilizada un cuarto de siglo después por el oidor de cuentas del convento de Nuestra Señora de Sandoval, de León.

Ya que $20.000 \mathrm{~ms} . / 485 \mathrm{~ms} .=4123 / 97$ C. o $41,237 \mathrm{C}$., que son, prácticamente, los 41 1/4 C. $-4 \mathrm{~d}$. del pago efectuado a Villacis.

Las equivalencias de los maravedís ya no suelen coincidir tanto.

La equivalencia del castellano de oro con respecto a la moneda valenciana surge de manera algo más complicada - unido a los ducados - en una carta real fechada en Alcalá de Henares el 12 de enero de 1498. Por ella se daba fe de que misser Felip Ponç, en su calidad de receptor de las conmutaciones y penitencias impuestas por los inquisidores de la corona de Aragón, había entregado al monarca 418 1/3 ducados de oro y 50 castellanos de oro, por un total de 10.151 sueldos y ocho dineros de moneda valenciana, que había cobrado en razón de su cargo"

418,33 D. $x 21 \mathrm{~s} .=8.785 \mathrm{~s}$.

$10.151 \mathrm{~s} .8 \mathrm{~d} .-8.785 \mathrm{~s} .=1.366 \mathrm{~s} .8 \mathrm{~d}$.

1,366 s. $x 12$ d. $=16.398 d .+8 d .=16.400 d$.

$16.400 \mathrm{~d} . / 50 \mathrm{C} .=328 \mathrm{~d}$. por castellano.

${ }^{10} \mathrm{AHN}$, Inq., leg. $568,1496, \mathrm{f}^{\circ} .70 \mathrm{r}^{\circ}$.

$11 \mathrm{AHN}$, Inq., libro 242, $\mathrm{f}^{\circ}, 13 \mathrm{v}^{\circ}-14 \mathrm{r}^{\circ}$. 
$328 \mathrm{~d} . / 12 \mathrm{~d} .=27,33 \mathrm{~s} .$, o sea $27 \mathrm{~s} .4 \mathrm{~d}$., el valor oficial que, como vamos viendo, tenía en moneda valenciana el castellano de oro.

Un anillo de oro, de 20 quilates de ley, que por una castellana de oro Benet Salvador había aceptado en prenda de Joan Torrelles, fue comprado por el médico Jaume Torres. En la subasta pública celebrada el 21 de enero de 1499, Torres (miembro de una célebre familia de médicos valencianos) pagó 41 sueldos por el anillo. De esta cantidad, el receptor descontó 6 dineros para el corredor público, Nicolau Rovell, que lo había subastado, y a Benet Salvador le devolvieron el importe de la castellana de oro. (Por cierto que el peso del anillo fue anotado como de una castellana de oro y media y 20 granos.) De modo que, una vez efectuados los descuentos susodichos, le quedaron al fisco real la cantidad de 13 sueldos 2 dineros ${ }^{12}$.

De forma que 41 s. $=492$ d. y 492 d. -6 d. $=486$ d.

486 d. -158 d. (= $13 \mathrm{~s} .2$ d. $)=328$ d., equivalencia del castellano de oro, o sea 27 s. 4 d. $V^{a}$.

Otra confirmación de la correspondencia entre castellanos y moneda valenciana la tenemos en el pago hecho el 23 de septiembre de 1500 al alguacil de la Inquisición de Cerdeña, García de Rebolledo. La cantidad era de $121 / 2$ castellanos que, según el registro, sumaban 17 f. 1 s. $8 \mathrm{~d}^{13}$.

$17 \mathrm{f} .1 \mathrm{~s} .8 \mathrm{~d} .=4.100 \mathrm{~d}$.

$4.100 \mathrm{~d} . / 121 / 2 \mathrm{C} .=328 \mathrm{~d} .=27 \mathrm{~s} .4 \mathrm{~d}$.

Asimismo, una gonella (saya) de estameña había sido empeñada por Joan Morata a Pedro Delgado, que después fue penitenciado por la Inquisición. El monto del empeño era de media castellana. En virtud de la confiscación automática de los bienes de los penitenciados, la saya ya había sido vendida por 26 sueldos, de manera que a Joan Morata le pagaron 12 sueldos 4 dineros, como parte de pago de la cantidad en que, aun cuando fuese en subasta, había sido vendida la gonella. El resto, que es lo que ahora nos interesa, era la parte correspondiente al medio castellano.

$26 \mathrm{~s} .=312$ d. Y 312 d. -148 d. $(=12$ s. 4 d. $)=164$ d., o sea $13 \mathrm{s.} 8$ d. $=27 \mathrm{~s} .4 \mathrm{~d} . / 2=1 / 2$ castellano, efectivamente.

Esta paridad se fue manteniendo a lo largo de los años del reinado de Fernando el Católico, y más allá. Por ello, todavía resulta más extraña la circunstancia señalada por Earl Jefferson Hamilton - ya mencionada antes- según la cual, en 1518, el oidor de cuentas del convento de Nuestra Señora de Sandoval (León), al asentar la entrada de un castellano a 485 maravedís, anotó: «No sé qué moneda es un castellano" ${ }^{14}$. Veamos, en todo

$12 \mathrm{AHN}$, Inq., leg. $568,1499, \mathrm{f}^{\circ}, 5 \mathrm{r}^{\circ}$.

13 AHN Inq., leg. $568,1500, f^{\circ}, 112 y^{\circ}$.

${ }^{14}$ El tesoro americano y la revolución de los precios en España, 1501-1650, p. 79 , núm. 100. 
caso, las cuentas de la receptoría inquisitorial de Valencia justo por aquellas fechas.

Joan Sanchis, alias de les Caçoletes, de profesión missatge, mandadero, había sido reconciliado con pérdida de sus bienes. De entre estos bienes, los inquisidores se habían apoderado de una bolsa llena de monedas de oro, de plata y menuts por valor de 70 sueldos y 6 dineros que, contabilizados en bloque, no nos dan el detalle de cada equivalencia monetaria. En cambio, Sanchis había encomendado algunas cantidades a diversas personas que, debidamente cobradas por el receptor inquisitorial, nos proporcionan más información. Así, misser Ferrando entregó, el 3 de octubre de 1517,8 castellanos de oro, de los que habían faltado, al peso, 21 granos que se valoraron en 6 sueldos y 2 d., así, descontados de los 8 castellanos, le quedaban netos al fisco real 10 libras 12 sueldos y 6 dineros.

$O$ sea, $y$ dicho de otra manera, que 8 castellanos de oro equivalían a $212 \mathrm{f}$. $6 \mathrm{~d}$. y, en dineros, a $2.544 \mathrm{~d} .+6 \mathrm{~d}$. $=2.550 \mathrm{~d}$.

Pero había sido preciso descontar el valor de 21 granos de peso que faltaban y que - según el receptor-eran igual a $6 \mathrm{~s} .2 \mathrm{~d}=74 \mathrm{~d}$. De hecho, matemáticamente no era del todo exacto, ya que, al haber 96 granos en el castellano, el valor de 21 granos había de ser de 71,75 dineros y no de $74 \mathrm{~d}$.

En efecto, 328 d. $/ 96 \mathrm{~g} .=35 / 12=3,417$ d. por g. y 3,417 d. $x 21 \mathrm{~g}$. $=$ $287 / 4=71,75 \mathrm{~d}$.

Sea como fuere, según las cuentas inquisitoriales, en el caso de haber estado completas las monedas su valor habría sido de $2.550 \mathrm{~d}$. $+74 \mathrm{~d}$. = $2.624 \mathrm{~d}$. Y $2.624 \mathrm{~d} . / 8 \mathrm{C} .=328 \mathrm{~d} .=27 \mathrm{~s} .4 \mathrm{~d}$., el valor del castellano de oro.

Dos semanas después, la correspondencia volvía a ser la misma para 8 castellanas que la señora Joana Valero había recibido asimismo de Joan Sanchis, de las cuales faltaron al peso $61 / 2$ granos. Los $61 / 2$ granos que faltaban fueron contabilizados a 1 s. 11 d., con lo que este valor guarda proporción con el del peso anterior, ya que, si 21 granos valían 74 dineros, en proporción $61 / 2$ granos habían de valer 23 dineros, lo cual, por cierto, arrojaría $28 \mathrm{~s}$. y $2 \mathrm{~d}$. para el castellano de oro entero, valía superior en $10 \mathrm{~d}$. a la equivalencia oficial ${ }^{15}$.

En otras zonas de la Corona de Aragón, el manejo continuado de la abundante documentación de índole económica que se nos ha conservado de aquella época, nos permite dar las equivalencias oficiales que regían para el castellano de oro en:
Aragón
$28 \mathrm{~s}$.
Mallorca
$40 \mathrm{~s}$.
Barcelona
30 s. 6 d.
Perpiñán
$42 \mathrm{~s}$.

${ }^{15}$ ARV, Maestre Racional, leg. 8.319, $f^{\circ} .10 v^{\circ}$. 
Convirtiendo a través del valor del ducado en Valencia y las demás zonas indicadas, sabemos que la relación de las respectivas monedas era:

En Aragón: $22 / 21=11 / 21 \mathrm{~s}$. $\mathrm{V}^{\mathrm{a}}$. por cada s. $\mathrm{J}^{\mathrm{a}}$. o aragonés.

En Barcelona: $24 / 21=11 / 7 \mathrm{~s}$. $\mathrm{V}^{\mathrm{a}}$. por cada s. $\mathrm{B}^{\mathrm{a}}$.

En Mallorca: $32 / 21=111 / 21 \mathrm{~s}$. V ${ }^{\mathrm{a}}$. por cada s. $\mathbf{M}^{\mathrm{a}}$.

En Perpiñán: $33 / 21=13 / 7 \mathrm{~s}$. $\mathrm{V}^{\alpha}$. por cada s. $\mathrm{P}^{\alpha}$.

Según esta relación, el valor del castellano de oro en Aragón, si hubiese guardado la proporción con su valor valenciano, habría sido de: $271 / 3 \times 1$ $1 / 21=82 / 3 \times 22 / 21=82 \times 22 / 3 \times 21=1.804 / 63=2840 / 63=28,6349206$ s. $\mathrm{J}^{\mathrm{a}}$. o sea, $0,6349206 \mathrm{~s}$. J". de más que los de la correspondencia oficial,

En Barcelona, $271 / 3 \times 11 / 7=82 / 3 \times 8 / 7=82 \times 8 / 21=656 / 21=31 \mathrm{~s}$. 2 1/2 d.; es decir, $81 / 2$ d. $\mathbf{B}^{\text {a }}$ de más que la equivalencia establecida oficialmente.

En Mallorca, $271 / 3 \times 111 / 21=82 / 3 \times 32 / 21=82 \times 32 / 63=2.624 / 63$ $=41 \mathrm{~s} .71 / 2 \mathrm{~d} ., 1 \mathrm{~s} .71 / 2 \mathrm{~d}$. $\mathrm{M}^{\mathrm{a}}$. más que la paridad oficial.

Y en Perpiñán, $271 / 3 \times 14 / 7=82 / 3 \times 11 / 7=82 \times 11 / 3 \times 7=902 / 21=$ 42 s. 11 1/2 d., o sea 11 1/2 d. Pa de más que la paridad oficial.

El hecho de tomar como base el valor del ducado en Valencia es debido a que era el centro financiero más importante de la Corona de Aragón ya que, como es obvio, su moneda era la más sana y fuerte de todas. Sin embargo, he establecido asimismo las relaciones entre los diversos valores monetarios del castellano de oro, tomando como base el valor del ducado en los demás sistemas monetarios.

A base del valor aragonés, el castellano de oro habría debido tener en Barcelona la paridad de 30 s. $61 / 2$ d. B ${ }^{\mathrm{a}}$; en Mallorca, 40 s. 8 1/2 d. $\mathrm{M}^{\mathrm{a}}$; y en Perpiñán, 42 s. P'. Este último es el único que coincide en este caso, junto con el barcelonés, que difiere tan sólo por 1/2 dinero.

A base del valor barcelonés, tenemos en Aragon 27,95833333 s. J".; en Mallorca, 40 s. 8 d. Ma; $y$ en Perpiñán, 41 s. 11 1/4 d. Pa.

A base del valor mallorquín, 27 s. 6 d. $\mathbf{J}^{\mathrm{n}}$, en Aragón; $30 \mathrm{~s}$. $\mathrm{B}^{\mathrm{a}}$, en Barcelona; y 41 s. 3 d. P'. en Perpiñán.

$\mathrm{Y}$ a base del valor perpiñanés, $28 \mathrm{~s}$. $\mathrm{J}^{\star \prime}$. en Aragón (valor lógicamente coincidente, en este caso); 30 s. $61 / 2$ d. Ba . en Barcelona; y 40 s. $81 / 2$ d. $\mathrm{M}^{3}$. en Mallorca.

\section{EL REAL DE PLATA}

Otra de las monedas castellanas más frecuentemente utilizadas en los países de la Corona de Aragón era el real castellano de plata. 
Había sido creado por el rey Pedro I de Castilla, pero en 1475 los Reyes Católicos los establecieron con una ley de 11 dineros y 4 granos, o sea $93 \%$, y una talla de 67 piezas por marco, características confirmadas por la pragmática de Medina del Campo de 1497. Aunque a partir de entonces su valor en moneda castellana pasó de 31 maravedís a 34 maravedís, paridad que conservó durante mucho tiempo.

En Valencia, su valor era superior en $5 \mathrm{~d}$. al real valenciano, de modo que equivalía a $1 \mathrm{s.} 11 \mathrm{~d}$. $\mathrm{V}^{\mathrm{a}}$,, o lo que es lo mismo $23 \mathrm{~d}$. $\mathrm{V}^{\mathrm{a}}$. Tomando como base la equivalencia de 1 D. = 21 s. $\mathrm{V}^{\mathrm{a}}$. y $1 \mathrm{D} .=375 \mathrm{~ms}$., la paridad valenciana casi coincidía con esta relación, excepto por 57/252 o 0,2261904 de más.

La equivalencia valenciana se mantuvo así hasta 1614 , a pesar de algún intento de cambio que, según E.J. Hamilton ${ }^{16}$, no tuvo efecto práctico alguno. Uno de estos intentos se halla reflejado en una crida del duque de Calabria, hecha pública en abril de $1536^{17}$, por la cual trataban de conseguir que el valor del real castellano fuese de 22 y no de 23 dineros.

Curiosamente, la documentación inquisitorial nos revela cómo, a pesar del exquisito cuidado que ejercieron los receptores de la Inquísición valenciana para ceñirse a las paridades oficiales, en ocasiones tenía que imponerse una equivalencia práctica de 22 dineros y no la oficial de 23 dineros por real castellano.

Así, a finales de 1500 , probablemente en diciembre, el receptor anotaba en sus cuentas: «item pongo en data que pague a Justo quatro reales castellanos, que en moneda reales de Valencia toman suma.VII. s. IIII., en virtut de hun mandamiento de los padres Inquisidores micer Johan de Monesterio e Rodrigo Sanz de Mercado, por el qual manda le sean paguados al dicho Justo por ciertos gastos que se fizieron en Murcia por aqueste Sancto Oficion.

Pues bien, 7 sueldos y 4 dineros $=84$ d. +4 d. $=88$ d. $Y 88$ d. $/ 4$ r.c. $=22$ dineros por real castellano.

Y el 29 de agosto de 1506, el receptor inquisitorial Amador de Aliaga anotaba cómo había entregado al alguacil del tribunal de Barcelona, Dionís Lázaro, la cantidad de 440 sueldos valencianos, «por quarenta libros llamados Directorios de la Inquisicion, a razon de seys reales castellanos por libro, que toman suma de los dichos .cccc. .xxxx. s. de moneda valencianas ${ }^{18}$.

De nuevo, el cambio había sido de 22 dineros por real castellano. Efectivamente, a razón de 6 reales por libro, 40 libros valían 440 sueldos

${ }^{16}$ El tesoro americano y la revolución de los precios en España, p. 125.

${ }^{17}$ Op. cit., ibid., núm. 30. ARV, Maestre Racional, Tesorería, leg. 356, ca. 8.538.

$18 \mathrm{ARV}$, Maestre Racional, leg. $8.352,4^{\circ}$, registro, $\mathrm{f}^{\circ}, 59 \mathrm{v}^{\circ}$. Incluido en mi tesis doctoral, sección Documentos, vol. III, p. $287-289$ y publicado en mi libro Inquisició espanyola $i$ cultura valenciana al País Valencià, Valencia 1978, p. 107-108. 
valencianos. Con lo que tenemos que 240 r. c. eran igual a $440 \mathrm{~s}$. y, por lo tanto, $440 / 240=1 \mathrm{r}$. c. $=1,83333 \mathrm{~s}$. Va. $=22 \mathrm{~d}$. O, 10 que es lo mismo, a razón de $11 \mathrm{~s}$. Va cada libro. $11 \mathrm{~s}, \times 12 \mathrm{~d}$. (para tener la equivalencia en dineros) $=132 \mathrm{~d}$. Y $132 \mathrm{~d}$. : 6 (por cada r. c.) $=22 \mathrm{~d}$., igualmente.

Pero esta equivalencia no era confirmada, al mismo nivel oficial, cuando se trataba de la correspondencia con otras monedas. Ni la volvemos a encontrar más adelante, algunos años más tarde, en que es la equivalencia oficial la que impera debido quizás al deterioro de la moneda valenciana, sobre todo por lo que a su peso se refería.

Sabemos que el valor del real siciliano era inferior al del castellano. Así queda reflejado alguna vez en la documentación, de modo que nos ayuda a deducir la equivalencia oficial de 23 dineros valencianos por cada real castellano.

En 1517, Joan Valero, de Jérica, había entregado a la receptoría inquisitorial dozientos reales castellanos. Pero, añade el registro, el uno era ciciliano, que no valia sino veynte dineros, que montan .ccc. $L X X X$. iii. s. 1 d. . O sea que, substrayendo $20 \mathrm{~d}$. de los 4.597 dineros que representan los 383 sueldos y 1 dinero indicados por el receptor, nos quedan 4.577 dineros para los 199 reales castellanos restantes y, por lo tanto $4.577 / 199=23$, los dineros correspondientes a cada real ${ }^{19}$.

Esta equivalencia oficial la volvemos a encontrar el 21 de octubre del mismo año, cuando la senyora Joana Valero entregó . LXXX. reales castellanos, los quales tenia encomendados del dicho Joan Sanchiz ${ }^{20}$, un missatge $\mathrm{o}$ mandadero reconçiliado a perdimiento de bienes. $\mathrm{Y}$ el receptor anotó en sus cuentas: 153 sueldos y 4 dineros. De modo que $153=1.836 \mathrm{~d}$. $+4 \mathrm{~d} .=1840$. Y 1840: $80=23 \mathrm{~d}$. por real, de nuevo la tarifa oficial.

Igualmente, Joan Sanchis había encomendado a Joan Valero, para que los entregase a Bartholome Sanchiz, hermano del dicho Joan Sanchiz, despues de las bodas de su nieta ${ }^{21}, 150$ castellanos y 25 ducados de oro, lo cual sumaba en conjunto 812 s. 6 d. Como sabemos que el ducado valía 21 sueldos, $21 \times 25=525 \mathrm{~s}$. que, substraídos de los $812 \mathrm{~s}$. anteriores nos dan $287 \mathrm{~s}$. que, reducidos a dineros son 3.444 . Más $6 \mathrm{~d}$. que quedaban de resto, 3.450 . Y $3.450 / 150=23$, vuelve a darnos la cantidad de 23 dineros para cada real castellano.

$$
\begin{aligned}
& 150 \text { r. c. }+25 \text { D. }\left(=525 \text { s. } V^{\circ} .\right) \\
& 525 \text { s. }=6.300 \text { d. }
\end{aligned}
$$

${ }^{19}$ ARV, Maestre Racional, leg. 8.319, $\mathrm{f}^{\circ}, 10$

20 ARV, Maestre Racional, leg. 8.319, $\mathrm{f}^{\circ}, 10$.

${ }^{21}$ El texto dice castellanos y no castellanas; y se refiere, efectivamente, a los reales de plata y no a las monedas de oro. 
812 s. 6 d. $=9.750$ d. y 9.750 d. -6.300 d. $=3.450$ d.

3.450 d $/ 150$ r. c. $=23$ d. $=1$ s. 11 d. $V^{\mathrm{a}}$.

\section{DE LAS PARIDADES REALES DE LAS MONEDAS CASTELLANAS EN LA CORONA DE ARAGÓN}

Las equivalencias en maravedís, establecidas oficialmente, eran:

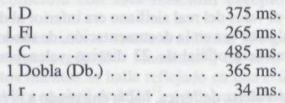

Las respectivas paridades de estas monedas, paralelamente a las disposiciones adoptadas oficialmente en los diversos territorios de la Corona de Aragón, nos ocuparán ahora en relación con sus correspondencias reales.

\section{ARAGÓN}

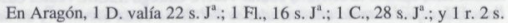
$\mathbf{J}^{\mathrm{a}}$. Sobre esta base, podemos deducir que, en Aragón, las paridades oficiales con respecto a las monedas castellanas, o las equivalencias en maravedís de otras monedas ajenas al sistema castellano, se hallaban del modo siguiente:

Florin

$1 \mathrm{D}=375 \mathrm{~ms}$, y 1 D. $=22 \mathrm{~s} . \mathrm{J}^{\mathrm{a}}$; $1 \mathrm{~s}$. Ja $.=17,04545455 \mathrm{~ms}$.

De modo que, 16 s. $\mathrm{J}^{\mathrm{a}}$. $=272,727272 \mathrm{~ms}$, con lo que resultaba que, en relación con la moneda castellana, el florín estaba sobrevalorado en 7 maravedís, 4 cornados y $31 / 2$ meajas ( $7,727272 \mathrm{~ms}$.)

Efectivamente, $17,04545455 \mathrm{~ms}$. x 16 s. $\mathrm{J}^{\mathrm{a}}$. $=272,727272 \mathrm{~ms}$. y $272,727272 \mathrm{~ms} .-265 \mathrm{~ms} .=7,727272 \mathrm{~ms}$.

\section{Dobla}

$1 \mathrm{Db} .=21 \mathrm{~s} . \mathrm{J}^{a}$. Y $21 \mathrm{~s} . \mathrm{J}^{\mathrm{a}}$. $\times 17,04545455 \mathrm{~ms} .=357,9545456 \mathrm{~ms}$, , con lo que relativamente estaba infravalorada en $7 \mathrm{~ms}$. y no mucho más de 2 1/2 meajas (7,04546 ms.).

Castellano de oro

$1 \mathrm{C} .=28 \mathrm{~s} . \mathrm{J}^{\mathrm{a}}, \mathrm{Y} 28 \mathrm{~s} . \mathrm{J}^{\mathrm{a}}, \mathrm{x} 17,04545455 \mathrm{~ms} .=477,2727271 \mathrm{~ms}$. 
De modo que, según la equivalencia, el castellano estaba infravalorado: $485 \mathrm{~ms} .-477,2727271 \mathrm{~ms}$. $=7,7272729 \mathrm{~ms}$, una cifra prácticamente idéntica a la sobrevaloración del florín.

\section{Real de plata}

$1 \mathrm{r} .=2$ s. Ja. Y 2 s. Ja. x 17,04545455 ms. por s. $=34,0909091 \mathrm{~ms}$. que con la ligera diferencia de casi 5 1/2 meajas, es la cifra que se había establecido para su equivalencia.

\section{VALENCIA}

En Valencia, las paridades de las monedas eran: 1 D. $=21 \mathrm{~s} . \mathrm{V}^{\mathrm{a}} ; 1 \mathrm{Fl}=$ $15 \mathrm{~s} . \mathrm{V}^{\alpha} ; 1 \mathrm{C} .=27 \mathrm{~s} .4 \mathrm{~d}$. $\mathrm{V}^{\alpha} ; \mathrm{y} \mathrm{Db} .=20 \mathrm{~s} . \mathrm{V}^{\alpha} ; 1 \mathrm{r}$. castellano $=1 \mathrm{~s} .11 \mathrm{~d} . \mathrm{V}^{\alpha}$.

\section{Florín}

1D. $=375$ ms. y 1 D. $=21$ s. V ${ }^{a}$, de modo que $1 \mathrm{~s} . \mathrm{V}^{\mathrm{a}}$. $=17,85714286$ ms. y 1 d. $\mathrm{V}^{\mathrm{a}}$. $=1,488095238 \mathrm{~ms}$. Por lo tanto, $15 \mathrm{~s}$. $\mathrm{V}^{\mathrm{a}}$ o $180 \mathrm{~d} \cdot \mathrm{V}^{\mathrm{a}}=$ $267,8571428 \mathrm{~ms}$.

Consiguientemente, en la realidad, en su paridad oficial valenciana el florín estaba sobrevalorado en 2 maravedís, 5 cornados y casi 1 1/2 meajas (2,8571428 ms.); o sea, casi 2 d. $V^{a}$. (1,9199999 d. $V^{\mathrm{a}}$., exactamente).

\section{Castellano}

En Valencia, el castellano de oro también estaba algo sobrevalorado. Con una paridad de $27 \mathrm{~s} .4 \mathrm{~d}$. $\mathrm{V}^{\prime \prime}$ o $328 \mathrm{~d}$. $\mathrm{V}^{3}$., ésto habría de dar - según la relación $375 \mathrm{~ms} .=21 \mathrm{~s}$. $\mathrm{V}^{\mathrm{a}}$. o 1 D. $-488,0952381 \mathrm{~ms}$., o sea 3 maravedís y poco más de $51 / 2$ meajas $(3,0952381 \mathrm{~ms}$.), lo cual equivale a poco más de 2 d. $V^{\mathrm{n}}$.

\section{Dobla}

Con la dobla sucedía al revés. Estaba infravalorada en $7,8571428 \mathrm{~ms}$. o 7 maravedís 5 cornados y casi $11 / 2$ meajas, o sea $51 / 4 \mathrm{~d}$. $\mathrm{V}^{\mathrm{a}}(5,279999962$ d. $V^{x}$, exactamente).

\section{Real}

En cuanto al real de plata, su verdadera equivalencia era de 34,22619047 ms., tan sólo 13 1/2 meajas (o 0,22619047 ms.) de más. 


\section{MALLORCA}

En Mallorca, 1 D. $=32$ s. M" $; 1$ Fl. $=22$ s. 6 d. $M^{n} ;$ y C. $=40$ s. $\mathrm{M}^{\mathrm{a}}$.

Por lo tanto, $1 \mathrm{~s} . \mathrm{M}^{\mathrm{a}}=11,71875 \mathrm{~ms}$. y 1 d. $\mathbf{M}^{\mathrm{a}}=0,9765625 \mathrm{~ms}$. De tal manera que el florin, en Mallorca, resultaba un tanto infravalorado, con una equivalencia de $263,671875 \mathrm{~ms}$. La disparidad con la reducción oficial era solamente de 1 maravedí y casi 2 cornados $(1,328125 \mathrm{~ms}$.).

En cuanto al castellano de oro, otra moneda castellana que tenía cotización en Mallorca, ésta se encontraba bastante infravalorada. Efectivamente, a una paridad de 40 sueldos mallorquines tenemos una equivalencia de 468,75 maravedís, en lugar de los 485 oficiales. Exactamente una infravaloración de 16 maravedís y $1 / 2$ blanca $\left(16,25 \mathrm{~ms}\right.$.), o sea $1 \mathrm{s.} 41 / 2 \mathrm{~d} . \mathrm{M}^{2}$.

\section{BARCELONA}

Por lo que se refiere a Barcelona, las reducciones de las equivalencias castellanas a moneda barcelonesa eran de 1 FI. a oficialmente 265 ms., por 17 s. B ; y el castellano de oro a 485 maravedís, por 30 s. 6 d. B ${ }^{2}$. La paridad del ducado en moneda barcelonesa era de $1 \mathrm{D} .=24 \mathrm{~s}$. $\mathrm{B}^{\mathrm{a}}$.

Por lo tanto, $1 \mathrm{~s} . \mathrm{B}^{\mathrm{A}}$. $=15,625 \mathrm{~ms}$. y $1 \mathrm{~d}$. $\mathrm{B}^{\mathrm{A}}$. $=1,302083333 \mathrm{~ms}$.

De modo que 1 florin resultaba igual a 265,625 maravedís, sobrevalorado en 3 cornados y 7 1/2 meajas solamente.

En cambio, el castellano de oro se hallaba menos ligeramente infravalorado en $8 \mathrm{~ms}, 2$ cornados y 6 meajas $(8,4375001 \mathrm{~ms}$. $)$.

Efectivamente, 366 d. x 1,302083333 ms. $=476,5624999 \mathrm{~ms}$., valor inferior del castellano, al cambio, en moneda barcelonesa, que, en este sistema monetario, se traducía por casi $6 \mathrm{l} / 2 \mathrm{~d}$. $\mathrm{B}^{2}$ en menos.

\section{PERPIÑÁN}

Finalmente en Perpiñán la equivalencia del ducado era de $33 \mathrm{~s}$. $\mathrm{P}^{\prime \prime}$., del florín $23 \mathrm{~s}, \mathrm{P}^{\prime \prime}$ y del castellano $42 \mathrm{~s}$. $\mathrm{P}^{\prime \prime}$. Así que, $1 \mathrm{~s} . \mathrm{P}^{\prime \prime} .=11,36363636 \mathrm{~ms}$. y 1 d. $P^{\prime \prime}=0,946969697 \mathrm{~ms}$.

Por lo tanto, 1 Fl. $=261,3636363 \mathrm{~ms}$. y 1 C. $=477,2727271 \mathrm{~ms}$., ambas monedas infravaloradas en relación con su paridad oficial. El florín, $3 \mathrm{~ms}$. 3 comados 8 meajas $(3,6363637 \mathrm{~ms}$. $)$ o $35 / 6 \mathrm{~d}$. $\mathrm{M}^{\mathrm{a}}$. Y el castellano, $7 \mathrm{~ms}$. 4 cornados $31 / 2$ meajas $\left(7,7272729 \mathrm{~ms}\right.$.) u $8 \mathrm{~d}$. $\mathrm{M}^{\mathrm{a}}$, o poco más. 


\section{CÁLCULOS MERCANTILES PARA LA REDUCCIÓN DE MONEDAS CASTELLANAS}

Está claro que, con esta compleja diversidad de equivalencias, se habían de suscitar buen número de dificultades a la hora de pasar cuentas y manejar tanta variedad de monedas. Obviamente, no se contaba con los conocimientos de que más tarde se dispondría. Aun así, la inventiva de los contables, especialmente más en el sector mercantil que en el oficial y burocrático, pronto dio lugar a una serie de ardides matemáticos, a base de reglas breves que facilitaban en algo, o en mucho, el manejo de las diferentes monedas con vistas a la obtención de una paridad exacta, matemática y rápidamente calculada.

Por lo que se refiere a la conversión del valor de las monedas castellanas en sus respectivas equivalencias de los diversos territorios de la Corona de Aragón, cuando todavía usaban exclusivamente cifras romanas para sus cálculos, los mercaderes valencianos podían emplear algunos sistemas en forma de "reglas generales" para convertir más rápidamente los castellanos de oro en libras valencianas. Es decir, para pasar de la moneda castellana a la valenciana. Siempre según la equivalencia de 27 s. 4 d. $V^{a}$. por cada castellano de oro.

El procedimiento era así: a la cantidad que se deseaba convertir en libras, se le añadía su tercera parte y, sumadas ambas, se contabilizaban ya como libras. A la cifra de este total, se la consideraba como medios sueldos y, debidamente convertidos, se les sumaba asimismo para obtener el resultado final. Una simple comprobación con los casos relativos a castellanos de oro, presentados anteriormente, nos indicará de qué modo funcionaban aquellas reglas generales.

En el caso de los 300 castellanos de oro, habrían sumado a esta cantidad su tercera parte, 100, y a la suma resultante, 400, la habrian tomado como la cantidad de medios sueldos que habría que añadir. Es decir, 400 medios sueldos que son igual a $200 \mathrm{~s}$. o, lo que es 10 mismo, 10 libras más.

$300 £ .+100 £ .+10 £ .=410 £$. que era, efectivamente, la cifra reducida a libras de los 8.200 sueldos que representaban los 300 castellanos de oro.

8.200 s. $=98.400$ d. y 98.400 d. $/ 328$ d. cada C. $=300$ C.

Para 50 castellanos, la operación era un poco más compleja:

$50 £ .+162 / 3 £ .=662 / 3 £ .+332 / 6 \mathrm{~s} .=66 £ .131 / 3 \mathrm{~s} .+1 £ .132 / 6 \mathrm{~s} .=$ $67 £ .262 / 3 \mathrm{~s} .=68 £ .6 \mathrm{~s} .8 \mathrm{~d} .$, o sea $1.366 \mathrm{~s} .8 \mathrm{~d} .=16.400 \mathrm{~d}$., la misma cantidad anteriormente calculada.

Todavía más complejo, pero fácilmente realizable, era el cálculo de la conversión de 41 1/4 C. -4 d. en libras valencianas. Aunque apuntando, desde ahora, que sus cálculos a base de fracciones eran entonces completa- 
mente diferentes de cómo los aprendimos en nuestra infancia (y tengo en prensa un estudio analizando el tema en profundidad), la operación había de dar los resultados siguientes:

$411 / 4 £ .+133 / 4 £ .=55 £$. Y $55 £+271 / 2 \mathrm{~s} .=55 £ .+1 £ .71 / 2 \mathrm{~s} .=$ 56 f. $71 / 2$ s. $=1.127$ s. 6 d.

Y 1.127 s. 6 d. -4 d. $=1.127$ s. 2 d., la cifra señalada en su momento.

Otro procedimiento para pasar de castellanos a libras valencianas, consistía en tomar el tercio de los castellanos y disponerlo en forma de suma bajo la cantidad indicada. Pero, de tal modo, que a cada unidad sobrante del tercio de la cifra indicada le daban el valor de $7 \mathrm{~s} .4 \mathrm{~d}$, que colocaban a la derecha de dicha tercera parte. Luego, cambiaban de posición la cifra del tercio calculado (sin sobrantes) y la movían hacia la derecha, con la salvedad de que doblaban el valor de su último guarismo. Y, finalmente, sumaban el total.

Por ejemplo, para convertir $368 \mathrm{C}$. en $£$. V $\mathrm{V}^{\mathrm{a}}$., la operación habría sido ésta:

$368 \mathrm{C}$.

122f. 14 s. 8 d.

$12 \mathrm{f} \quad 4 \mathrm{~s}$.

502 f. 18 s. 8 d.

En efecto, dado que 1 C. $=328$ d. V ${ }^{a}, 368$ C. $x 328$ d. $=120.704$ d. y $120.704 \mathrm{~d} . / 12 \mathrm{~d} .=10.058 \mathrm{~s} .8 \mathrm{~d} . \mathrm{V}^{\mathrm{a}}$.

10.058 s. 8 d. V $\mathrm{V}^{\mathrm{a}} .=502$ £. $18 \mathrm{~s} .8 \mathrm{~d}, \mathrm{~V}^{\mathrm{a}}$.

A la inversa, es decir para pasar de las $£$. Va. tomaban la cuarta parte de las $£$., haciendo caso omiso de los sueldos y dineros indicados. Pero no eran cuartos exactos, como calcularíamos hoy, sino que procedían así: $1 / 4$ de $5=1$; sobraba 1 que, con 0 , hacía 10 . Pero este mismo 1 que era $1 / 4$ de 5 , se restaba de 10 , con lo que quedaban $9 ; 1 / 4$ de 9 , o sea 2: sobraba de nuevo 1, que con el 2 que quedaba de la cifra original, hacía 12. De éstos, se les restaba $1 / 4$ de 9 , o sea 2 . Seguían quedando 2 unidades, a cada una de las cuales se les daba el valor de $7 \mathrm{~s} .4 \mathrm{~d}$., que se colocaban a la derecha de la cifra obtenida. Luego, repetían esta cifra desplazándola un lugar a la derecha, pero doblando el último número y contabilizándolo como sueldos. La suma de estas cantidades, o sea 134 C. 18 s. 8 d. en el ejemplo que nos ocupa, se restaba de las libras indicadas, $502 \mathrm{f}$. $18 \mathrm{~s}, 8 \mathrm{~d}$. Va., y el resultado eran los castellanos: 
502 f. $\quad 18 \mathrm{~s}, 8 \mathrm{~d}$

122 C. 14 s. 8 d.

12C. $4 \mathrm{~s}$.

134 C. 18 s. 8 d.

$368 \mathrm{C}$.

Un sistema, ciertamente tan complicado, presentaba sus excepciones, y una de éstas era el de las cifras con ceros. Como en el caso de $800 £$. que, al convertirlas en $\mathrm{C}$., convenía que siempre sobrase alguna unidad para combinarla con el 0 subsiguiente. De modo que $1 / 4$ de 8 se consideraba que era 1 (y no 2). Por lo tanto, sobraban 4 que, con el 0, daba 40. De nuevo, su cuarta sería 10, con lo que no se podría operar con el 0 final. De modo que se restaba 1 de 40 , lo cual daba $39,1 / 4$ de 39,9 y sobraban 3 que, con el 0 final, eran 30 , al que había que sustraerle 9 , con lo que quedaban 21 para operar. $1 / 4$ de 21 , es 5 y sobraba 1 , al que se le daba el valor de 7 s. $4 \mathrm{~d}$. Luego, procedían de manera análoga al ejemplo anterior, moviendo un lugar las cifras del ucuarto», pero doblando el último número y dándole el valor de sueldos. Sumadas estas dos últimas partidas, el resultado se restaba de la cifra en $£$., con lo que el total final eran los castellanos que se buscaban con la reducción: $585 \mathrm{C} .10 \mathrm{~s}$. (Efectivamente, porque $1 \mathrm{C}$. = 27 s. 4 d. $V^{3}$.

$800 \mathrm{f}$.

\begin{tabular}{|c|c|c|c|}
\hline $\begin{array}{r}195 \mathrm{C} . \\
19 \mathrm{C} .\end{array}$ & $\begin{array}{r}7 \mathrm{~s} . \\
10 \mathrm{~s} .\end{array}$ & . 4 & \\
\hline $4 \mathrm{C}$. & $17 \mathrm{~s}$. & . & \\
\hline
\end{tabular}

$585 \mathrm{C}, 10 \mathrm{~s}$.

En Aragón, era posible por medio de estos ardides contables reducir $\mathbf{f}$. a C. y C. a f., así como C. a florines y Fl. a C.

En el primer caso, procedían así: deducían la diferencia existente entre la paridad en sueldos del castellano y la subdivisión de la libra; 0 sea $28-20=8$. Calculaban qué parte proporcional de $1 \mathrm{f}$. era 8 , o sea 275 (20 s. : 2/5). Calculaban entonces $2 / 5$ de la cifra dada, que sumaban a la misma. En el caso de que hubiese algún sobrante en los quintos, se le daba el valor de $4 \mathrm{~s}$. por unidad. Por ejemplo, en el caso de tener que calcular cuántas $f$. eran en Aragón 70 C., habrían procedido así: 
$70 \mathrm{C}$.

$28 \quad(=2 / 5$ de 70$)$

$98 \mathrm{f}$

En la operación inversa, el paso de moneda aragonesa a moneda castellana, computaban en primer lugar la diferencia en sueldos entre el valor oficial de la £. Ja. y el C., que, como hemos dicho, era de $8 \mathrm{~s}$. Procedian entonces a calcular qué proporción del C. representaban 8 , o sea $2 / 7 \mathrm{C}$. Calculaban entonces los $2 / 7$ de la cantidad dada para su conversión, que restaban de la cifra de castellanos y el resultado final era la solución buscada. Así, para saber cuántos C. eran en Aragón $97 £$. Ja., dado que $8 \mathrm{~s}$. Ja. (la diferencia de valor entre $£$. Ja. y C.) era $2 / 7$ C., tenían 27 C. 20 s, como resultado de $97: 2 / 7=194 / 7=1895 / 7=$ 27,71428571 C. Sustraídos de 97 £. Ja., como si todo fueran castellanos, producían 69 C. $8 \mathrm{~s}$, de modo que cada quinta o séptima parte sobrante sabían que habían de contabilizarla como $4 \mathrm{~s}$.

Siempre en el mismo Aragón, para la reducción de castellanos a florines y viceversa, buscaban normalmente la diferencia entre la paridad de ambas monedas, calculaban qué parte de un florín era aquella cifra; y sobre esta base deducían la parte proporcional de la cantidad dada que, una vez computada, le era añadida para tener el total final.

Así, en el caso de querer estimar cuántos florines eran, en Aragón, $453 \mathrm{C}$, como la diferencia de paridad entre C. y Fl. era $12 \mathrm{~s}$. $\mathrm{J}^{\mathrm{z}}$ y esto era $3 / 4$ Fl., tenían que $453: 3 / 4=1.359 / 4=3393 / 4=339 \mathrm{Fl} .12 \mathrm{~s}$. que, sumados a 453 , daban 792 Fl. 12 s.:

$453 \mathrm{C}$

339 Fl. $12 \mathrm{~s}$.

792 Fl. 12 s. J".

En la operación inversa, como 12 son $3 / 7$ de la paridad de C., 792 Fl. : $3 / 7=339 \mathrm{C} .12 \mathrm{~s}$. que, sumados a $453 \mathrm{C} .=792 \mathrm{Fl} .12 \mathrm{~s}$.

Para las monedas barcelonesas, dadas sus paridades, no disponían de los mismos ardides contables y por ello procedían a deducir sus reducciones a base de los complicados medios propios de la época.

\section{EQUTVALENCIAS Y COMPUTACIÓN DE LAS MONEDAS ESPAÑOLAS}

Tenemos, pues, que aun cuando coexistiesen también unas paridades divergentes, en tiempos de Fernando el Católico había unas equivalencias 
oficiales que, normalmente, se cumplían por todas partes en y para la moneda castellana.

Según las diversas zonas, el castellano de oro tenía las siguientes equivalencias: en Castilla, 485 maravedís; en Aragón, 28 sueldos jaqueses; en Barcelona, 30 sueldos y 6 dineros barceloneses; en Perpiñán, 42 sueldos perpiñaneses; $y$ en Valencia, 27 sueldos y 4 dineros valencianos.

En cuanto a las paridades reales, se hallaba infravalorado en Aragón, en Mallorca, en Perpiñán y en Barcelona, pero sobrevalorado en Valencia.

La dobla tenía en Castilla una equivalencia de 365 maravedís; en Aragón, valía 21 sueldos jaqueses; y en Valencia, 20 sueldos valencianos. Se hallaba infravalorada en ambas zonas monetarias.

Y, el real de plata, equivalía en Castilla a 34 maravedís; en Aragón lo cotizaban a 2 sueldos jaqueses; y en Valencia, a 1 sueldo y 11 dineros valencianos, 5 dineros más que la moneda valenciana de la misma denominación. Algo sobrevalorado en Valencia, el real tenía una paridad casi exacta en el sistema aragonés.

Por lo que se refiere a otras monedas, primordiales en los territorios de la Corona de Aragón, el ducado tenía en Castilla una equivalencia oficial de 375 maravedís. Y el florín, de 265 maravedís; en Aragón, el ducado valía oficialmente 22 sueldos jaqueses; en Barcelona, 24 sueldos barceloneses; en Mallorca, 32 sueldos mallorquines; en Perpiñán, 33 sueldos perpiñaneses; $y$ en Valencia, 21 sueldos valencianos.

El florín se cotizaba a 16 sueldos jaqueses en Aragón; 17 sueldos en Barcelona; 22 sueldos y 6 dineros en Mallorca; 23 sueldos en Perpiñán; y 15 sueldos en Valencia.

De acuerdo con las relaciones monetarias entre unos sistemas y otros, así como las diversas paridades oficiales, el florín resultaba algo infravalorado en Mallorca y en Perpiñán, pero sobrevalorađo en Aragón, Barcelona y Valencia.

En el bien entendido de que, dados los procedimientos contables, excesivamente rudimentarios al principio y luego mantenidos en las oficinas de la burocracia oficial, los resultados de las transacciones monetarias variaban de manera a menudo considerable, según que, para computar las reducciones y equivalencias, utilizasen unas paridades $\mathbf{u}$ otras, como monedas de referencia. Y ello a pesar de que se basasen, escrupulosamente, en las igualdades oficiales establecidas para aquellas monedas.

Tan sólo en los cambios con los países lejanos, a través de las letras de cambio, y con los procedimientos bancarios — bastante más sofisticadosque entonces comenzaban a florecer y a establecerse, hemos podido ir viendo cuáles eran las relaciones monetarias reales y el grado de inflación o deflación que experimentaban las divisas monetarias de la época.

Como era natural, fueron los comerciantes y los banqueros quienes, con su práctica mercantil, adoptaron primeramente los nuevos métodos que 
iban surgiendo en las diversas zonas de sus relaciones económicas. La complejidad de la metodología misma que iban adoptando y desarrollando, hizo que fueran aprendiendo poco a poco los nuevos procedimientos. Es por esta razón que hemos consagrado un apartado entero a algunas de las prácticas que fueron aceptando, así como algunos de los ardides contables que, con la necesaria y exacta prontitud de sus cálculos, formaban parte de su nuevo proceder mercantil.

A la espera de publicar el análisis detallado de la estructura concadenada de estas prácticas mercantiles, las páginas que anteceden se presentan como una primera manifestación de los estudios llevados a cabo a lo largo de estos últimos años. 